\title{
Advances in Cognitive Psychology Relevant to Education: Introduction to the Special Issue
}

\author{
Pooja K. Agarwal
}

Published online: 12 August 2012

(C) Springer Science+Business Media, LLC 2012

It is September 2012 - let us take stock of the past 55 years in the field of education. In 1957-1958, the Soviet launching of Sputnik led to the National Defense Education Act and interest in teaching advanced math and science to all students. In 1983, a report entitled "A Nation at Risk" was released and caused widespread panic about our failing education system. In 2001, the No Child Left Behind (NCLB) Act ushered in a new era of standardized testing and accountability. And today, states are being granted "waivers" from specific provisions of NCLB to provide increased flexibility in the hopes of drastically improving educational outcomes around the country. Currently, we are witnesses to profound educational "experimentation," for example with charter schools, voucher programs, educational technology, new standards and assessments, revamped educator evaluations, and the growth modeling and analysis of student data. Year after year, decade after decade, we implement new initiatives for our nation's education system, yet we often fail to obtain significant improvements.

In the current era of flexibility and experimentation, we have a golden opportunity as cognitive and educational scientists to take what we have learned over the course of at least 100 years about human learning and memory and apply it to the "real world" of education. Our research has drastic implications for education and by "giving our research away," we could add an element of scientific rigor to the discussion of education, encourage tougher standards for teacher training and professional development programs, increase understanding of and decision making based on student data (rather than simply "the more data, the better"), and ultimately move toward a higher quality education system for our nation. In doing so, we may finally move away from a system in which educational practices are based on history and doctrine. Instead, I hope that someday, we will look to cognitive and educational research when we demand scientific rigor in education and seek evidencebased practices.

As an initial step, this special issue of Educational Psychology Review "gives away" cognitive psychology research related to education. Each article included herein reviews recent advances in learning and memory research, and addresses the potential implementation of

P. K. Agarwal ( $\square)$

Department of Psychology, Washington University in St. Louis, St. Louis, MO 63130, USA

e-mail: pooja.agarwal@wustl.edu 
cognitive strategies in authentic classroom settings. In the first paper, Doug Rohrer describes the strategy of interleaving, in which the presentation of a concept is followed by the presentation of a different concept (rather than the repetition of the same concept), subsequently improving students' discrimination among similar concepts, terms, and principles. Next, Shana Carpenter and colleagues review the strategy of spaced practice and discuss the potential for optimal gaps or delays between presentations of the same concept. In a related vein, Lisa Son and Dominic Simon also discuss spacing, while focusing on individual learners and their self-awareness or metacognition of spaced practice. In the fourth paper, Jeffrey Karpicke and Phillip Grimaldi review research related to retrieval-based learning and they emphasize the direct and indirect effects of retrieval on learning. Next, Katherine Rawson and John Dunlosky further consider retrieval practice, including the optimal amount of practice testing for individual students. In an extension to authentic classrooms, Pooja Agarwal and colleagues discuss the implementation of retrieval practice in middle school classrooms and present some general recommendations for applied research. To round out the issue, Elizabeth Marsh and colleagues highlight exciting research about learning from fiction, including recommendations and areas of caution. Additionally, Gary Phye offers his insights about each review article and he aptly encourages us to consider model-based reasoning as we move forward from here.

I thank Dan Robinson, editor of Educational Psychology Review, for inviting me to serve as guest editor and providing me with infinite wisdom, support, encouragement, and patience over the course of this yearlong project. I also wish to acknowledge Henry L. Roediger for his steadfast mentorship and advice. Finally, I am indebted to the authors and reviewers for sharing their wealth of knowledge, expertise, and dedication to rigorous cognitive psychology research relevant to education.

In closing, unless we begin to think about education differently, we will continue adding money, programs, and computers, hoping for a quick fix. Instead, we need to conduct rigorous research in a variety of educationally relevant areas and widely disseminate evidence-based practices. I hope that the compilation of this special issue is one small step in the right direction. 